board his most exact and finely executed drawings as if they were insignificant doodles.

John's entomological drawings are well-known, but the broader scope of his artistic ability is not perhaps so fully appreciated. An exhibition here at the College in 1976 consisted of over 150 examples of his work and included anatomical studies, scenes from hospital life, animal drawings and publicity material. A small display of his drawings can be seen outside the lecture theatre. For his artistic ability John Grundy was recently awarded an honorary doctorate of Queens University Belfast.

The post of lecturer in entomology was and still is unique in the Royal Army Medical College in being one of the few teaching posts occupied by a civilian. This has the great advantage of ensuring continuity of experience, policy and teaching methods. During his 25 years at the College John Grundy lectured and demonstrated to about 1100 Senior and Junior Army Medical Officers, to nearly 2000 National Service Medical Officers and to a considerable number of laboratory technicians and hygiene assistants.

A great many people within the Army Medical Services are grateful to him for providing them with a basic and essential knowledge of medical entomology. I am particularly grateful to him for laying the foundations of what is now a thriving and integral part of medicine and public health in the Armed Services.

\section{Reflections on Some Human Ectoparasites}

\section{JAMES R. BUSVINE DSc, FIBiol}

The title of this talk being somewhat vague, it may be useful to explain what it will be about. The ectoparasites in question are mainly those with which my researches have been concerned over many years: human lice, the bed bug, fleas and the itch mite. Like John Grundy, my primary concern was to assist in finding ways of controlling these pests, or to instruct others in their biology to facilitate such control efforts. Therefore I ought to spend some time considering the changing situation in this important practical matter. However, I think that in this lecture I may be allowed to discuss certain less obviously practical aspects of the ectoparasites in regard to their specification. For both parts of my talk, some explanation seems due for the bracketing together of these particular anthropods of public health importance; and I will begin with the practical issues.

As you may know, I was for many years a member of the Entomology Department of the London School of Hygiene and Tropical Medicine. The medi- cal entomology courses we taught were mainly concerned with disease vectors and were largely orientated towards the tropics where such diseases are most severe. Of my four kinds of ectoparasite, only

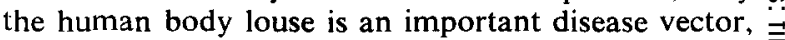
the others being merely vexations in themselves. However, the characteristic common to all of them is the fact that they can potentially be eliminated by improvements in personal hygiene. In contrast, no conceivable improvement in cleanliness or house construction could ensure freedom from yellow fever, onchocerciasis or malaria. No one would subscribe to Belloc's tongue-in-cheek rhyme:

How idiotic; can quinine

Replace cold baths and sound hygiene?

But those anthropods which have become adapted to life on our bodies, or permanently resident in our dwellings, are indeed vulnerable to improvements in hygiene. Let us consider what has happened to them over the past years.

\section{Human body lice}

If we could alter the habit of many decades, these should be called clothing lice, since they spend near $\$$ all their time on clothing, mostly on the garment nex to the skin. This has important consequences. Thuse the monograph on Lice by the late Professor Buxto shows the decline to zero of cases of typhus in Britaif during the nineteenth century. This occurred lons before its connection with lice was demonstrated b Nicolle in 1910. The elimination of this dread disease therefore owed nothing to entomologists or even to physicians, but was merely due to the fact that, over the period in question, people came to wash their underwear more frequently and thoroughly. Incidentally, my former colleague John Maunder has pointed out that, in those days, washing clothes entailed boiling them, so that all lice present would be killed, whereas this high temperature is not reached with modern biological washing powders. However, I cannot feel that there is much danger of general lousiness, unless hygienic facilities collapse, as they did for soldiers in the trenches of the First World War.

When a second World War appeared inevitable, Buxton foresaw the possibility of lice spreading among the civilian population, if air raids were to destroy laundering facilities. $M v$ involvement in the subject began when $I$ joined him in a search for lasting protection from lice, which was eventually solved when we got a sample of DDT. This soon proved a marvellous weapon for checking lousebourne disease epidemics in places where low stan- o dards of hygiene existed. However, while modern $N$ insecticides have achieved great success in quelling N such epidemics, they cannot be relied upon for $\underset{\sigma}{\sigma}$ 
routine control measures, because their regular and widespread use results in the appearance of resistant strains of lice. Therefore, one must hope for general improvement in hygiene; but this presents formidable problems in communities where people are so poor as to own only one set of clothing and where laundering in hot water is unknown and perhaps impracticable.

\section{Head lice}

From evidence to be discussed later I consider the head louse to be a species distinct from the body louse. In any case, the public health problems associated with them are quite different, since the head louse has never been the primary cause of epidemics of louse-bourne disease. On the other hand, they are less responsive to improvements in standards of hygiene, because water used to wash the hair is not hot enough to harm them and, as John Maunder remarks, only results in cleaner lice.

When I worked with Buxton, although our main target was the more dangerous body louse, the head louse was not forgotten. He arranged for me to try out some of our insecticidal preparations on infested school children and also on recruits to the WAAF.

I found that head lice could readily be controlled by insecticides suitably formulated so as not to smell unpleasantly or spoil the appearance of the hair, otherwise they were soon washed off by the indignant patients or their mothers. First, there was Lethane Hair Oil and later an aqueous preparation of $\mathrm{HCH}$, which had a long and useful life of some 35 years. until resistant lice appeared. I set John Maunder on to this problem and he overcame it with a malathion preparation. However, I am sure that he would be the last to be complacent about the present situation.

During the $1970 \mathrm{~s}$, evidence came to light of increased incidence of head lice, not only in England, but in France, the Netherlands, Denmark, Russia and both West and East Germany. Further afield, similar increases have been noted in parts of the USA, Canada and Chile. To some extent these depressing observations could be ascribed to resistance; but I doubt if this is the complete explanation, as I shall discuss later.

\section{Crab lice}

Information on the incidence of head lice is relatively available, at least for school children, who are regularly inspected in some countries. But it is much less easy to assess the prevalence of crab lice. Some information was obtained in the early 1960s at an English venereal diseases clinic, where some 10,000 patients had been examined between 1954 and 1966. The percentage infested rose from $0.8 \%$ to $3.2 \%$ over this period, incidence being highest in girls aged 15 to 19 and men of 20 and over. It may well be thought that patients at a venereal diseases clinic were not a representative sample of the population and perhaps more likely to be infested. However, some recent discrete enquiries by my former colleagues at the London School of Hygiene and Tropical Medicine suggest that crab lice are more common among students than might be expected and may be increasing. A similar trend in Denmark is suggested by the fact that enquiries about the insect have been growing, from 1 or 2 a year in 1968-9, to 10 in 1973,15 in 1974 and 32 in 1981.

There should be no difficulty in eradicating infestations of these lice by gamma $\mathbf{H C H}$ lotions or pyrethroids and there is no evidence of resistance. However, radical elimination of the pest is handicapped by mental attitudes of the people infested. There may be, I suppose, some uncouth individuals more or less indifferent to 'crabs'; but more important are the majority who are distressed at acquiring an infestation with its connotation of sexual licence (known be bohemian Frenchman as le papillon d'amour). Sham prevents them seeking professional help and they resort to ineffectual self-treatment.

\section{Bed bugs}

For perhaps a dozen years of my life, I became intimately acquainted with human lice. The word intimately is justified by the fact that I used to feed them personally in small cages strapped round mF ankles. Fortunately, another parasite with which became familiar, the bed bug, could be fed on rabbit blood.

In the years just before the last War there had been a kind of crusade against bed bug infestations in the slums. Another of my old professors, J W Munro, used to call it the 'slum-bug', pointing out that it tended to perpetuate bad housing conditions, since the presence of the bug drove away the better tenants. Both the Medical Research Council and the Ministry of Health set up committees to investigate the problem and supported research on the subject. A great deal was learnt about bug biology, much of it by my former colleague $\mathrm{C} G$ Johnson; but no very satisfactory control measures were found. Because the bugs were hidden in inaccessible crevices by day, they were protected from most of the insecticides available at the time apart from the dangerous hydrogen cyanide gas, which in any case $\frac{9}{7}$ could not be successfully used in leaky ill-constructed houses. Accordingly, some of those concerned with the problem advocated vigorous attacks with soap and water; in other words, better hygiene by the housewife.

As with lice, the situation was entirely changed $\underset{N}{N}$ by the introduction of DDT and other synthetic 
insecticides which formed residues lethal to bugs which crawled over them subsequently and which could be used easily and cheaply in human dwellings. As a result, bug infestation in most temperate countries was substantially reduced but I am sorry to say that the trouble smoulders on in persistant cases of infestation. There are hardly any statistics available, but in Denmark where records are kept by the Government Pest Control Laboratory, there are sugestions of increases, shown by enquiries about bugs rising from about 20 a year in the 1960 s to 262 in 1982. Moreover, in many places, and especially in tropical countries, control is handicapped by resistance to many convenient residual insecticides.

\section{Fleas}

The so-called human flea, Pulex irritans, was formerly so common as to become the subject of a good deal of ribald literature. It must have been familiar to Linnaeus, since he used its size (as well as that of the louse) to describe certain beetle species ('Magnitude pulcis' etc.). I believe they were still quite common in my younger days and I can remember finding a specimen feeding on my hand atfer a visit to a cinema in Brighton about 1932. (Rash flea, it ended up on a microscope slide!) Generally speaking, however, this flea has declined in prevalence in recent years. In 1955, I reported that, of 28 flea specimens sent to me for identification, only 8 were Pulex irritans. More recently, the Danish Pest Control Laboratory reported in 1976 that of 2294 flea specimens, only $1 \%$ were human fleas and $90 \%$ of them were cat or dog fleas. It was also stated that infestations by these fleas of pets were becoming more and more prevalent; and the 'epidemic' continues to grow, according to recent information, in Denmark as well as in the UK.

Pulex irritans is a big flea and it used to be the performer in flea circuses, the owners of which grew anxious for specimen as the supply declined. One such gentleman applied to my department about 30 years ago offering "a fair price for a good bold flea." Our puny Xenopsylla cheopis were too tiny to handle and we had not managed to rear Pulex irritans, which is difficult to do. Bacot managed it, way back in 1914 , but no one else had succeeded until 1958, when Hudson \& Prince followed Bacot's method and reached colonies; and they also managed to feed them with citrated human blood under membranes.

The usual reason put forward for the decline of the human flea is improved standards of housekeeping especially with the help of the vacuum cleaner. However, recent experiments in Denmark have shown that a vacuum cleaner cannot exterminate an infestation as quickly. as some insecticidal treatments. Nevertheless, I do not think that modern insecticides can claim the credit for the reductions. And, unfortunate- $\stackrel{\mathbb{D}}{\circ}$ ly, its role as a human torment has been taken by $\bigcirc$ the cat and dog fleas, especially the former. Thesefleas can be attacked by pyrethrid dusting or by insecticidal collars; but the simplest measure would $\vec{F}$ seem to be improved cleansing of the pet's sleeping place.

\section{Some conclusions}

Dittmann and Eichier, discussing the reasons for rising incidence of head lice in East Germany, list ${ }^{\text {क }}$ the following possible reasons. (1) Ignorance of the $\overrightarrow{0}$ population. (2) Lack of statistical data to warn auth- $\overrightarrow{-}$ orities. (3) Increased tourism. (4) More crowded cre- $\vec{\omega}$ ches and schools. (5) Neglect of hair care.

Perhaps it may seem cynical or reactionary to ascribe the wave of scabies and promiscuity among? young people. However, some evidence for this $\vec{\omega}$ may be adduced in the widespread rise in gonorrhoea reported for many countries in 1972 (Fig 2); and N also the more recent alarm about the AIDS disea $\vec{\omega}$ in the USA.

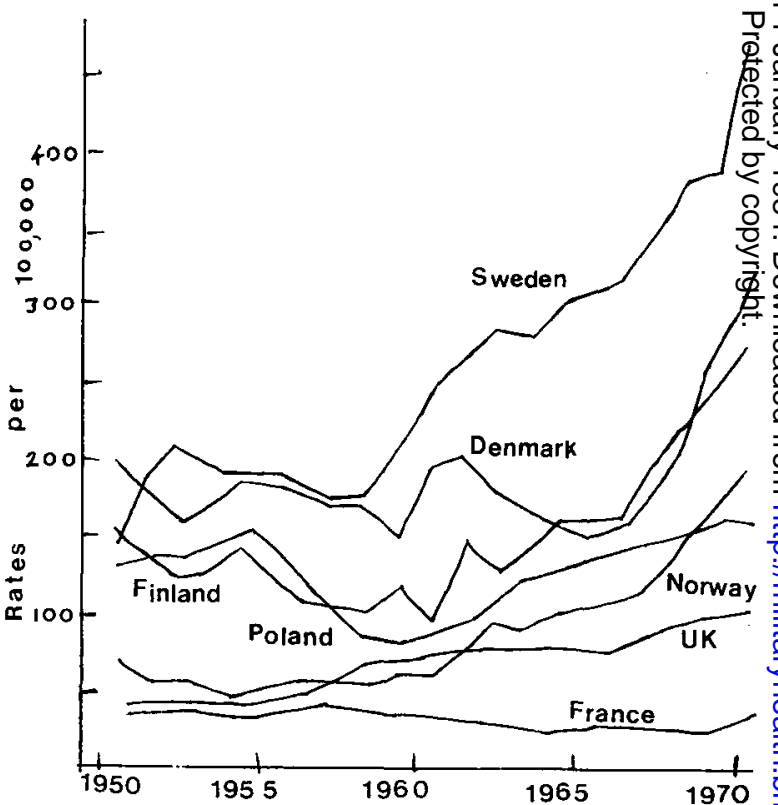

Fig. 1 Incidence of Gonorrhoea in various countries, from Guthe 1972.

I may be mistaken, but whatever the cause, I feel $O$ confident that neither ectoparasites nor venereal disease would be tolerated by individuals or families with good standards of hygiene. Moreover, it is unlikely that freedom from these pests can be ensured by medicaments or insecticides alone. The final res- N ponsibility rests with the individual, especially the housewife and mother. 


\section{Some evolutionary trends}

I would like now to turn to a more academic view of these ectoparasites and consider their evolution into the status of human parasites. First, we should remember that the great burst of evolutionary diversity of the insects occurred about 300 million years ago, and some 150 million years before the advent of birds and mammals. Most of the insects had by then settled to living on vegetation or on each other as predators. A few, however, transferred their attentions to the new forms of life and became blood suckers, most of them catholic in choice of host, but later some became specialisd parasites of a few closely related hosts. Man appeared on the scene so late that he has attracted the undivided attention of only a very few of these parasitic forms, notably three kinds of lice.

\section{Human lice}

The suckling lice are conservative in their adaption to a particular host, and, while they may feed on a strange species, very few are normally able to complete development. And, since insect parasites seem to evolve more slowly than vertebrates, it is often possible to infer the evolutionary relationships of their hosts from the closeness of the affinities of their parasites.

There are, however, a few exceptions in the form of transfers to unrelated hosts. For example, one species of a family otherwise all parasitic on Australan marsupials, has become adapted to dogs, presumably via the dingo. Again, species of Pediculus are exclusively human parasites; but one form is found on South American spider monkeys, which are not even closely related to man. It has been suggested that the transfer occurred as a result of pet monkeys being kept by the native Indians. Another transfer was accomplished experimentally about 30 years ago when, to avoid feeding human lice on themselves, some American scentists selected a strain which can be reared on rabbits.

This was accomplished with some difficulty, with high mortality among the lice at first. More recent work has shown, rather surprisingly, that human body lice will survive quite well on mice or hamsters, though they all die after a meal of guineapig blood.

It is fairly certain that our lice have been inherited from pre-human ancestors, since their only close relatives occur on primates. The three kinds of lice which attack man have different habitat preferences. The crab louse has chosen regions of the body bearing coarse hairs, set widely apart, the pubic and axillary regions. There are occasional infestations of the eyelashes, with similar types of hairs. The anatomy of this louse has become adapted to grasping widely separate, coarse hairs. It was formerly thought, too, that its sedentary habits discouraged wandering, but recent observations have shown that it can be surprisingly active in darkness.

The other two kinds of human lice present a taxonomic puzzle, to which I have contributed some evidence at both ends of my career, in 1948 and 1978. Body lice are generally larger a character probably developed to accommodate bigger blood meals. Unlike head lice, which can feed at any time, body lice cannot feed well when clothing shifts about while the host is in motion, or of course, if clothes are removed at night. Some of these size measurements overlap, so that those of very small body lice are less than those of very big head lice. Scholl, however, in 1955 found that the dimensions of the hard parts of the legs gave good separation of the two types, and I have subsequently adopted this criterion.

Hitherto, all investigations of this problem had compared quite separate collections from hair or garments of different people maintained in laboratory cultures. But, in 1976 on a visit to Ethiopia, I was able to obtain specimens of both types from the same infested individuals (Fig 3). These showed that populations of the two forms retained their differences

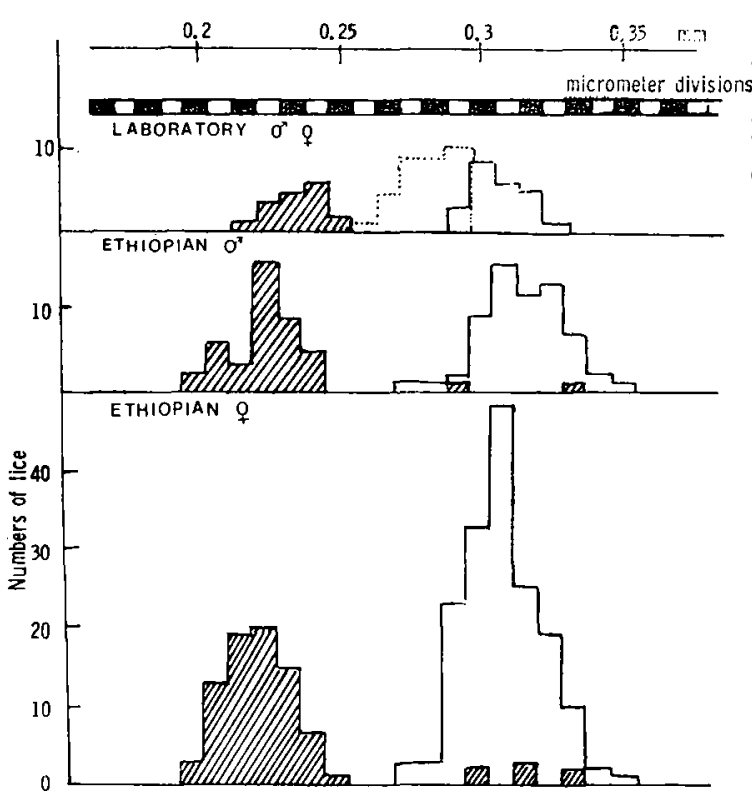

Fig. 2 Histograms showing distribution of sizes of louse tribiae (top) from crossing laboratory strains of lice. Hatched: head lice. Clear: body lice. Dotted F: hybirids. (Middle and bottom) lice collected from double infestations in Ethiopia. Hatched: from hair. Clear: from garments. (Note absence of hybrid size range.) From Busvine 1978. 
even with opportunities to interbreed and there was no evidence of hybridisation. Now, it had long been known that they will interbreed in artificial conditions, when confined together in small pill boxes, but my evidence suggests that they do not do so naturally Therefore, I claim them to be separate species as follows: 'A group of individuals so separated genetically from all other such groups that it would not form with them a single interbreeding community if given the opportunity under natural conditions.

Presumably the head louse was the original form and the so-called body louse found a new ecological niche when our ancestors lost their hair and began to wear clothing. The origin of this change is not clear, since in other cases ectoparasites separating into two species, with different locations on the same host, have been assumed to have occurred on quite separate populations of the host, which eventually reunited after the two parasites had become genetically isolated.

\section{The itch mite}

I cannot claim to have worked with Sarcoptes scabies though I visited Professor Mellanby's unique institute in Sheffield during the Second World War. Here he studied the transmission and treatment of scabies, with the help of conscientious objectors who volunteered to become infected, and scabetic soldiers. The two groups got on together surprisingly well, as he describes in his book "Human Guineapigs." I was duly infected with a female mite under the skin of my wrist, where she survived well until Mellanby sent me 'some medicament to rectify my predicament.' His medicament was benzyl benzoates; but I think that gamma $\mathbf{H C H}$ is more commonly used now. I know of no certain evidence of resistance in the mites: but if this should occur, there are three or four effective alternative treatments.

As regards the prevalence of scabies in recent decades, there sems to be a certain parallel with head lice. In both cases, the high levels discovered at the time of World War II were substantially reduced by vigorous action by the public health authorities, using effective treatments. Later, levels were found to be rising in the 1970s; in Britain. Cchechoslovakia and parts of the USA (Fig 1) Kenneth Mellanby believes that this recent surge can be ascribed to an inherent periodicity of the infection. After a period of high incidence, it is said, many patients have acquired a kind of immunity, so that the infection tends to die out. Presently, a new generation of young, uninfected people arise, quite susceptible to the disease, so that another increase begins. This is helped by the fact that physicians have become unfamiliar with scabies and do not always diagnose it easily.
Personally, I find it difficult to comprehend this theory of cyclical waves of prevalence, which seems to suggest that new generations of non-immunes come in batches, instead of continuously. In an attemp? to get more recent information, I wrote to Mellanby $\overrightarrow{\vec{F}}$ who replied that he had lost touch with the subject and to Dr. Milton Orkin, an American expert. He re $\frac{5}{0}$ plied: 'The condition continues in the Unitects. States, although there is waxing and waning. We hach originally anticipated that the cycle would be ove? in 1980 (as predicted by previous cycles) but apparw ently, because of lower incidence, it continues int $\vec{D}$ the 1980s. One of the problems that seems to be progressive is the increasing difficulty in eradicating mini-epidemics from nursing homes'. This last sen tence suggests the possibility of incipient resistance? which is not easy to verify. I have written to Dr. Oro kin suggesting possible ways of checking it.

The whole matter involves various problems, such as the reason for our ancestors losing their bodyn hair, about which there are one or two speculativi theories.

Fleas

As with lice, the zoogeography and host assoga tions of fleas provide some interesting clues to evolution of the parasites and their hosts. Fleas, however, are less host specific than lice and the provide examples of convergent evolution, thatofs adaption of different taxa to particular hosts $=0$ environments. Thus, birds in arboreal nests tend읙웅 have fleas which are poor jumpers, and animals in underground burrows often have blind fleas.

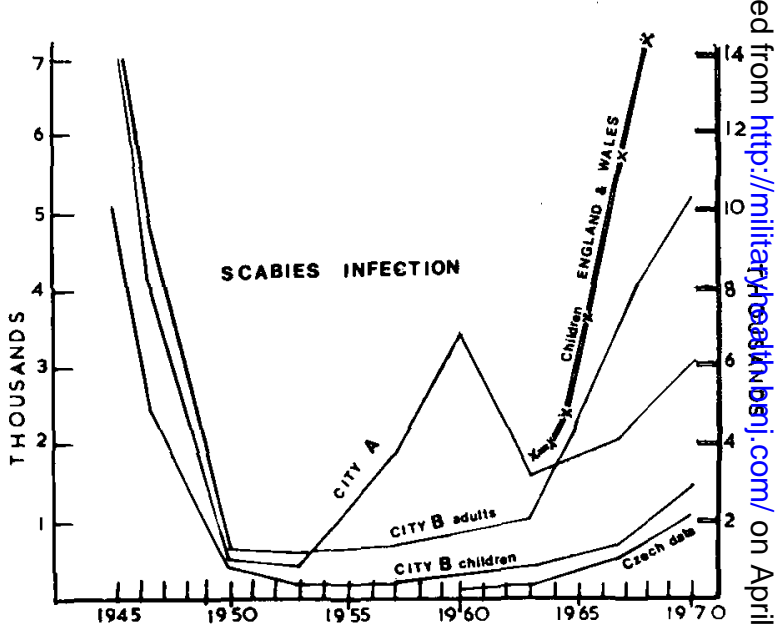

Fig. 3 Reported incidence of Scabies. Cities A \& B $^{\text {D }}$ from table 1.2 in Busvine 1980. Total for children in England and Wales from DHSS Report 1974. FoE Czechoslovakia, from Palika \& Marka 1971. 무 
The so-called human flea is certainly less adapted to us than our lice. It can be found on various wild animals, such as foxes, wolves, skunks, badgers, some large rodents and especially swine. Significantly, I think Pulex attacks no primate other than man. A recent study suggests that Canada were the original hosts and, since most species of Pulex occur in the New World, it seems likely that $P$. irritans originated in Central America and spread across the Bering Straits into Asia and Europe (Fig. 4). It is true that specimens have been found in a 10th Century Viking grave, but probably the invasion occurred well before then.

We cannot guess when or how the association began. Perhaps the domestic pig was involved, since it is a good host, as many farmers will confirm. It has been pointed out that the human dwelling in its primitive form is a reasonable substitute for a pigsty, and man and pig share several other parasites.

It is of interest to note that there is a very closely related species in America, $P$. simulans, and it is possible that a species complex exists. The specific identity of $P$. simulans is proved by small anatomical differences maintained in double infestations (irritans, simulans) on the same animal.

\section{Bed Bugs}

Bed bugs belong to a large order of insects which have their mouthparts adapted for piercing plants and sucking their sap. Some of them, however, developed the predatory habit, piercing other insects and sucking their blood. Sometimes these will prick the human skin if handled, and certain groups have become completely dependent on feeding on the blood of warm-blooded animals. Two of these groups regularly attack man, having most probably developed the habit independently. One is the Triatominae or cone-nose bugs of the Neotropics, and the other is the bed bug species of the family Cimicidae.

The cone-nose bugs have not evolved far from their plant feeding ancestors, which they resemble in general appearance. On the other hand, the bed bug group of families includes forms with reducedo wings and cryptic habits. One family, the Polycteni- $\frac{}{\Phi} \vec{\omega}$

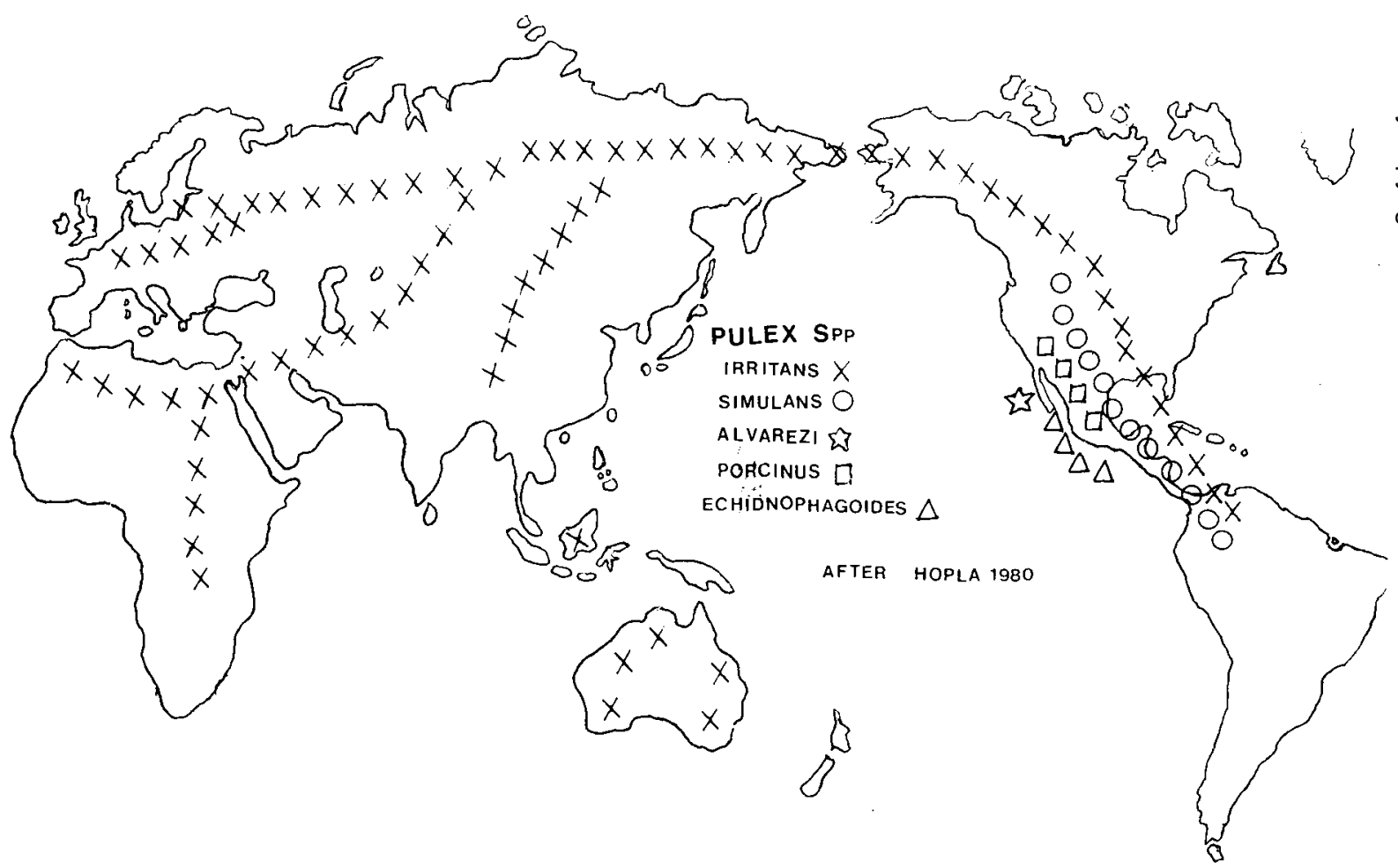

Fig. 4 Distribution of species of Pulex. From Hopla 1980 
dae, is exclusively parasitic on tropical bats, in whose fur they spend their entire lives. They are flattened creatures, wingless and viviparous.

The cimicid family is small with only 74 species in 22 genera. Most of the Old World forms are parasitic on bats, which were probably the original hosts of the group, while about half the New World species have become adapted to feeding on cave or cliff-living birds. These facts suggest that bed bugs became associated with man during a cave-dwelling period of pre-history and followed him into dwellings of his own construction. It seems probable that this occurred in the Near or Middle East from whence bugs had spread into the Mediterranean region by classical times, and they are referred to by various Greek and Latin authors. Subsequently they spread across Europe, reaching Germany in the 11 th Century and France in the 13th Century. The earliest recorded occurrence in England was in 1583 when, according to Thomas Mouffet's famous "book "Theatrum Insectorum," some ladies in Mortlake were dismayed by their strange appearance.

The bed bug is quite ready to feed on other warmblooded hosts apart from man, so that it can be reared in the laboratory on rabbits, guinea pigs or even chickens. On the other hand, it is not found on wild animals, so that its adaption to man is genuine.

The pigeon bug of Western Europe, Cimex columbarius, is closely similar to the bed bug. Separation of the two species depends on the ratio of certain measurements of the antenna and head. The two forms can be crossed but do not do so readily, and there is reduction of fertility in the hybrids. It is possible that this species became adapted to domesticated doves or pigeons in Roman times and the isolation due to separate breeding sites has been maintained long enough to result in $a$ degree of genetic isolation.

The tropical bed bug. Cimex hemipterus, probably originated in South East Asia and has been transported to other tropical regions round the World, though it is not known when this happened. It has similar habits to $C$. lectularius, but is biologically less viable and cannot establish itself in the temperate regions, whereas $C$. lectularius is colonising many tropical countries. The two forms are quite distinct species; though they will copulate, they do not produce viable offspring. Neither species is involved in disease transmission, but both are obnoxious because of their bites. Methods of control are similar and each has developed resistance to some insecticides. Thus, two quite distinct species pose almost identical public health problems, in contrast to the closely allied head and body lice, which constitute very different problems.
Before leaving this subject, we may note that few bug parasites of birds will occassionally bite peô ple, though they cannot permanently exist on huma blood. Thus, the genus Oeciacus, closely related Cimex, contains $O$. hirundinis, the martin bug and $O$. vicarius, the swallow bug, both of which cam wander from nests on dwellings and cause a nuisance from their bites.

The Itch Mite: The mites or Acarina havis exploited various modest habitats available to veræ small arthopods. Unlike the insects which, by the development of wings, have acquired a powerful way of exploring their environment, mites have very limited powers of movement. They rely ont passive migration by currents of wind or water of very occasionally, on the bodies of larger animal Most of them inhabit soil or surface debris, feedin on plant or animal remains and their habitats extend. over a great range, from nearly bare mountain top through forests, meadows, swamps and lakes to the sea shore.

Some mites have become predators of the ves arian or saprophytic forms and a few have becomre parasitic. The first steps towards an ectoparasitic asseciation with man can be guessed from the fact 草得 people whose work involves handling mite-infest materials tend to suffer dermatitis due to tempogat invasions. The mites in question may normally vegetarian forms, feeding on various stored prodock such as copra, grain, cheese or dried fruit. From such chance invasions, one can imagine an adventition mutation allowing mites to feed on sebaceous sears tions or debris in their follicles. Some kinds of mang in animals are due to mites which have become adapted, for example, the curious worm-like form? which cause demodectic mange; the group include Demodex folliculorum, common in the hair follicles of the human eyebrows and forehead, but normal without apparent harm. Finally, the sarcoptic type of mite actually burrows into and feeds on the upper layers of the skin.

Perhaps the best authority for the affinities of the Sarocoptidae is the Belgian Professor A. Fain, wh believes that Sarcoptes scabiei is primarily a huma parasite and closely related to a group of similar forms found on monkeys. It is true that forms ve similar to $S$. scabiei have been found infesting domes tic animals as different as carnivores, ruminants and marsupials. Fain, however, points out that he haf never found examples in wild animals, but only to captive or domesticated ones. The morphology these forms shows some variability, but his theory is that all belong to the polymorphic species Sarcoptos scabiei and some populations have transferred from man to closely associated animals and are in the pro cess of becoming adapted to them. It is noteworthy 
that people tending infested animals can become infested from them, sometimes for long periods.

\section{Remarks on speciation}

In conclusion, I would like to make some general remarks on speciation. We have noted various instances of ectoparasites transferring from one host to another, and, in the case of man, from or to domestic animals, pets, or captives in menageries. With human lice, there is further adaption to different parts of the same host. In all cases, these adaptions represent small evolutionary steps.

If we believe in the evolutionary origin of the species, it is clear that there must be situations where the separation of new forms is incomplete, so that there is difficulty in deciding at what point a polymorphic species becomes a group of sub-species, and when the designation of species can be justified. Of the examples I have mentioned, there is little difficulty in recognising the common and tropical bed bugs as distinct species. Less obvious are the Cimex species lectularius and columbarius, or Pulex irritans and simulans, the forms of Sarcoptes infesting animals, and Peduculus humanus and capitis.

Regarding the last pair, it may be significant that I had to go so far to find double infestations on the same individuals, because in most places, head lice and body lice tend to infest different sections of the population. Body lice are found on rather dirty vagrants, often elderly; head lice, commonly, on young people, often quite cleanly. Thus, future isolation of the two kinds of lice seems assured.

Perhaps I may be allowed a pragmatic plea for separate speciation. Since the public health involved are so different, many hygienists would welcome the simpler scientific names, rather than the cumbersome Pediculus humanus humanus and Pediculus humanus capitis. Finally, I would point out that my views have been accepted by both an American and a German authority on lice.

\section{REFERENCES}

1 Buxron P A. The Louse. London: E Arnold 1947.

2 Busvine J R AND Buxton P A. Bri Med 1942; 1: 464.

3 Busvine J R et al. Med Offr 1948; 79: 121.

4 MaUnder J W. Community Med 1971; 126: 148.

5 Donaldson R J. J R Soc Hith 1976; 96: 55.

6 Lamizana M T and MoucheK J. Med Malade Infect 1976; 6: 48.

7 HoORNWEg $\mathrm{J}$ et al. Nederland T. Geneesk 1975; 119: 1534.

8 Hallas T et al. Ent Med 1977 45: 77.

9 PAlika et al. J Hyg Epidem Microbiol Immunol 1971; 12: 54.
10 Weyer F. Ztschu Angew Entom 1978; 65: 1 .

11 Dittman I and Eichler W. Beitr Angew Entom 1978; 19: 1 .

12 Orkin $M$ et al. Scabies and Pediculosis. London: Lippincott 1977.

13 ANON J. Infect Dis 1976; 6: 21.

14 HOPPER J M. Can J Publ Hlth 1971; 65: 159.

15 SCHeONe H et al. Bol Chil Parasit 1973; 28: 31.

16 Fisher I AND MORTON R S. Br J Vener Dis 1970; 16: 362.

17 BURgess I et al. Community Med 1983; 5: 238.

18 Medical Research Council: Report on Bedbug Infestation. London: HMSO 1942.

19 Ministry of Health. The Bedbug: Rpt Publ Hlth Med Subj No 72. London: HMSO 1934.

20 Johnson C G. J Hyg (Lond.) 1941. 41: 345.

21 BUSVINE J R. Sanitarian 1978 (May).

22 Busvine J R. Bull Wld Hlth Org 1958 : 19: 1041.

23 Thompson R T. Antenna 1983; 1: 108.

24 Busvine J R. Mon Bull Min Hlth 1955; $14: 178$.

26 ВАсот A W. J Hyg (Lond.) 1914; 3: 447.

25 ANON. Ann Rpt. Danish Pest Control Lab. Copenhagen 1977.

27 Hudson B W and Prince F M. Bull Wld Hlth Org 1958; 19: 1129.

28 Mellanby K. Parasitology 1944; 35: 197.

29 Mellanby K. Human Guinea Pigs. London: Merlin 1973.

30 BUSVine J R. Insects and Hygiene. London: Chapman and Hall 1980.

31 Anon. Health of the School Child. London: Dept Educ Sci 1974.

32 Palika P and Merka V. J Hyg Epidern Microbiol Immnol 1971; 15: 457.

33 EPSTEIN E AND ORKIN M. ibid 1977; 21: 100.

34 SCHROETER A. ibid 1977; 21 : 150.

35 MellanBy K. ibid 1977; 21: 200.

36 Guthe T. Postgrad Med J 1972; 1: 7.

37 Hopkins G H. Proc Zool Soc. London 1949; 119: 387.

38 Culpepper G H. Amer J Trop Med 1948; 28: 499.

39 Ludwig $\mathrm{H} \mathrm{W}$. Control of Lice and Louse-borne Disease. Pan American Health Organisation Scientific Publication No 231973.

40 Busvine J R. Parasitology 1948; 39: 1.

41 BUSVine J R. Sytemic Entom 1978; 3: 1.

42 Hopla C E. Fleas ed Traub and Starke. Rotterdam: Balkema 1980.

43 Rothschild M. Proc $R$ Ent Soc Lond 1973; 38: 29.

44 Holland G P. Mem Ent Soc Can 1964; 6́1:

45 Usinger R L. Monograph of the Cimicidae. Barkeley California: Thomas Say Foundation 1965.

46 Johnson C G. Trans $R$ Ent Soc Lond 1939; 89: 543.

47 Fain A. Acta Zool Path Anwterp 1958; 17:

48 SouthWartzman R M. ibid 1977; 56.

49 SCHAFER C W. Trans $R$ Soc Trop Med Hyg 1978; 72: 669. 